\title{
Validation of the Italian HeartQoL: a short health-related quality of life questionnaire for patients with ischemic heart disease
}

\author{
Francesco Fattirolli ${ }^{1}$ - Alessia Argirò ${ }^{1} \cdot$ Maria Elisabetta Angelino ${ }^{2} \cdot$ Gianluigi Balestroni $^{3} \cdot$ Francesco Giallauria $^{4}$. \\ Daniela Miani $^{5}$. Carlo Vigorito ${ }^{4}$ Lucrezia Piccioli $^{1,2,3,4}$. Franco Tarro Genta ${ }^{6}$. Stefan Höfer ${ }^{7}$. Niccolò Marchionni ${ }^{1}$. \\ Neil Oldridge ${ }^{8}$
}

Received: 30 March 2021 / Accepted: 27 May 2021 / Published online: 10 June 2021

(c) The Author(s) 2021

\begin{abstract}
The psychometric properties of the core disease-specific 14-item Italian HeartQoL health-related quality of life questionnaire have been evaluated in this study. The Italian version of the HeartQoL, the MacNew questionnaire, and the Hospital Anxiety and Depression Scale were completed by 472 patients (angina, $N=183$; myocardial infarction, $N=167$; or ischemic heart failure, $N=122$ ) who were recruited in five Italian centers (Florence, Veruno, Turin, Udine, and Naples) between 2015 and 2017. Patients with myocardial infarction reported significantly higher HeartQoL scores than patients with angina or ischemic heart failure. Floor and ceiling effects were always minor on the HeartQoL global scale and physical subscale with moderate ceiling effects on the emotional subscale in the total group and in patients with myocardial infarction. The bifactorial structure of the original HeartQoL questionnaire was confirmed with strong physical, emotional, and global scale $\mathrm{H}$ coefficients $(>0.50)$. The HeartQoL scales demonstrated optimal internal consistency (Cronbach's alpha $>0.84)$. Convergent and divergent validity were confirmed. Discriminative validity was not confirmed for age, largely confirmed for sex, and fully confirmed for anxiety, depression, and distress. The Italian HeartQoL questionnaire demonstrated adequate key psychometric attributes of internal consistency reliability and validity in Italian-speaking patients with ischemic heart disease.
\end{abstract}

Keywords Health-related quality of life - Italian HeartQoL questionnaire · Angina pectoris · Myocardial infarction Ischemic heart failure $\cdot$ Validation

Francesco Fattirolli

francesco.fattirolli@unifi.it

1 Department of Experimental and Clinical Medicine, University of Florence and Cardiothoracovascular Department Azienda Ospedaliero-Universitaria Careggi, Largo Brambilla 3, 50141 Firenze, Italy

2 Psychology Unit, Istituti Clinici Scientifici Maugeri, Turin, Italy

3 Psychology Unit, Istituti Clinici Scientifici Maugeri, Veruno, Italy

4 Department of Translational Medical Sciences, Federico II University of Naples, Naples, Italy

5 Cardiology Unit, University Hospital S. Maria Della Misericordia, Udine, Italy

6 Department of Cardiology Istituti Clinici Scientifici Maugeri, Turin, Italy

7 Department of Medical Psychology, Medical University of Innsbruck, Innsbruck, Austria

8 College of Health Sciences, University of Wisconsin-Milwaukee, Milwaukee, WI, USA

\author{
Abbreviations \\ AP Angina pectoris \\ HRQL Health-related quality of life \\ IHD Ischemic heart disease \\ IHF Ischemic heart failure \\ MI Myocardial infarction
}

\section{Background}

Critical steps in improving the quality of health care include evidence-based, patient-centered, and systems-oriented care [1]. Incorporating this approach has changed medicine in all areas, from everyday practice, where shared decision making has become essential and recommended by guidelines [2] to clinical trials where patients are involved in Steering Committees [3]. Major treatment goals for patients with cardiovascular disease include a focus on health status which includes symptom burden, functional limitations, and health-related quality of life (HRQL) [4, 5]. Health status 
typically is evaluated with patient-reported outcome questionnaires through which patients may express feelings about their health condition without adulteration or interpretation by clinicians [6].

Both generic and disease-specific patient-reported outcome questionnaires can be used to evaluate and compare the health status. Generic instruments, such as the SF-36 Health Survey (SF-36) [7, 8], are designed for use in healthy populations, different disease populations as well as between healthy populations and populations with various diseases. On the other hand, disease-specific instruments, such as the Seattle Angina Questionnaire [9] and the Minnesota Living with Heart Failure questionnaire [10] provide more relevant disease-specific information than generic instruments. However, there is a need for core disease-specific questionnaires which permit between-diagnosis comparisons within a given disease with a single questionnaire, for example, the MacNew [11] and, more recently, the HeartQoL [12, 13] in patients with ischemic heart disease (IHD).

The HeartQoL questionnaire was developed with the objective of assessing HRQL using a single instrument in patients with angina pectoris (AP), myocardial infarction (MI), or ischemic heart failure (IHF). The HeartQoL Project was conducted between 2002 and 2011 in European and English speaking regions in two phases: first, a cross-sectional survey to identify items for questionnaire inclusion on the basis of three previously validated instruments [12], the Seattle Angina Questionnaire, [9] the MacNew Heart Disease Health-related Quality of Life Questionnaire (MacNew) [11], and the Minnesota Living with Heart Failure questionnaire [10], and a second phase to evaluate the HeartQoL questionnaire's psychometric properties [13]. The result was a bifactorial, 14-item questionnaire that was reliable, valid, and responsive in patients with AP, MI, or IHF [13]. These results have been recently confirmed in German [14] and Chinese [15] and also in other clinical contexts, such as atrial fibrillation [16], implantable cardioverter defibrillator recipients [17], and valve surgery [18].

To optimize their use as both research and clinical tools, patient-reported HRQL questionnaires need to meet basic attributes such as reliability and validity [19]. Reliability is considered the degree to which a questionnaire is free from random error with internal consistency reliability the intercorrelations of items at one point in time. Validity is the degree to which the instrument really measures what it purports to measure and includes convergent validity (the degree to which two theoretically related measures are in fact related), divergent validity (the degree to which two dissimilar measures can be differentiated) and discriminative validity (does the questionnaire adequately discriminate between groups that should or should not differ). The purpose of this study was to examine the factor structure, reliability, convergent, divergent, and discriminative validity of the Italian version of the HeartQoL questionnaire in patients with AP, MI, or IHF.

\section{Methods}

\section{Patients}

Patients diagnosed with IHD $[n=472]$ were recruited at five sites in Italy (Florence, Veruno, Turin, Udine, and Naples) from 2015 to 2017 . The eligibility criteria were extracted from the original cross-sectional survey phase of the HeartQoL Project [12] and included:

(a) currently being treated for AP [20] with an objective measure of IHD (e.g., previous MI, exercise testing, echocardiogram, nuclear cardiac imaging, or coronary angiography); or

(b) had experienced a documented MI between one to six months previously; or

(c) currently being treated for IHF with evidence of left ventricular dysfunction (ejection fraction $\leq 40 \%$ by invasive or non-invasive testing) and an objective measure of IHD (e.g., exercise testing, echocardiogram, nuclear cardiac imaging, or coronary angiography).

The patients were $\geq 18$ years, able to complete the selfadministered battery of HRQL questionnaires in Italian, without hospitalization in the last 6 weeks, without serious psychiatric disorder as well as no current substance abuse as identified by the referring physician. The Ethics Committee in each study site approved the project and informed consent was obtained from all patients.

\section{Patient-reported questionnaires}

\section{Sociodemographic and clinical variables}

Demographic characteristics of age, sex, family status, education, employment, and cardiovascular risk factors (diabetes, hypercholesterolemia, hypertension, physical inactivity, and smoking) were self-reported by patients.

\section{HeartQoL}

The Italian version of the disease-specific HeartQoL was used in the HeartQoL Project [12] and in this study to measure HRQL. The HeartQoL is a bi-dimensional instrument 
with a 10 -item physical subscale and a 4-item emotional subscale that, when combined, provides the 14-item global scale [12]. The responders answer the question of how much they are bothered by each of the 14 HeartQoL questionnaire items on a 4-point scale ranging from "bothered a lot" $(=0)$ to "not bothered" $(=3)$ with higher scores indicating better HRQL. Both the global scale and the subscales were calculated as the mean of the scored items.

\section{Hospital anxiety and depression scale (HADS)}

The HADS is a 14-item self-assessment questionnaire including an anxiety and a depression subscale that together generate a common score for general distress; the Italian version was used in this study $[21,22]$. The items are answered on a scale ranging from 0 to 3 with higher scores representing higher levels of anxiety or depression. A subscale cutoff score $\geq 8$ identifies patients with symptoms of depression or anxiety [22] and a global cutoff score $\geq 12$ indicates "general" distress.

\section{MacNew}

The MacNew Questionnaire is designed to assess patient's feelings about how IHD affects daily functioning [11]. It contains 27 items with a global HRQL score and physical limitation, emotional and social function subscales, scored from 1 (low HRQL) to 7 (high HRQL) [23, 24]. Using forward-backward translation, the MacNew questionnaire had been translated into Italian and validated as part of the HeartQoL Project [25].

\section{Statistical analyses}

Means and standard deviation (SD) are reported for continuous variables and frequencies for categorical variables. Categorical sociodemographic and clinical variables were analyzed with Pearson's Chi-square test while continuous variables and scale means were examined with analyses of co-variance (ANCOVA) with post hoc Bonferroni correction adjusting for age, sex, risk factors, and disease severity within diagnosis. A two-sided $p$ value of $<0.05$ was applied for statistical significance. The data were analyzed using IBM SPSS Statistics 24 and STATA 14.
The evaluation of the psychometric properties of the Italian HeartQoL followed criteria recommended by the Scientific Advisory Committee [19]. Floor and ceiling effects of the HeartQoL are considered moderate when $>15 \%$ patients report the lowest score $(=0$; floor $)$ or the highest score $(=3$; ceiling) [26]. A confirmatory Mokken scale analysis, using Loevinger's coefficient $H$ of $\geq 0.50$ considered a "strong," 0.49-0.40 a "moderate," and 0.39-0.30 a "weak" scale [27], was performed to assess whether the established two-factor structure of HeartQoL [12] could be confirmed in the Italian HeartQoL. Internal consistency reliability was determined using Cronbach's alpha with values of $\geq 0.70$ acceptable for group and $\geq 0.90$ for individual comparisons [28]. The strength of the correlations between HeartQoL and related (convergent) as well as unrelated (divergent) constructs was assessed with Pearson coefficients $(r<0.10=$ no correlation, $r=0.10-0.29=$ low correlation, $r=0.30-0.49=$ moderate correlation, $r \geq 0.50=$ high correlation) with Steiger's test used for differences in correlations [29]. Discriminative validity was tested for using the "known-groups" approach [26] with paired t tests used to compare HeartQoL scores with two-level variables and one-way ANOVA used to compare three-level variables. The following discriminative validity hypotheses test whether significantly higher HeartQoL scores are reported:

1. by younger than by middle-age or older patients,

2. by male patients than by female patients,

3. by patients with MI than by patients with either AP or IHF,

4. by patients reporting higher MacNew HRQL scores (top $33 \%$ of actual scores) than by lower scores (bottom $33 \%$ of actual scores),

5. by patients without HADS anxiety $($ score $<8$ ) than by patients with HADS anxiety (score $\geq 8$ )

6. by patients without HADS depression (score $<8$ ) than by patients with HADS depression (score $\geq 8$ ) and

7. by patients without HADS general distress (score $<12$ ) than by patients with HADS general distress (score $\geq 12$ ). 


\section{Results}

\section{Patient characteristics (Table 1)}

A total of 472 patients with documented AP $(N=183$, $38.8 \%)$, previous MI $(N=167,35.4 \%)$ or IHF $(N=122$, $25.8 \%$ ) were eligible for the validation of the Italian HeartQoL Questionnaire. The mean age of the total cohort was $65.4 \pm 12.5$ years. The majority of patients (74.6\%) were male, most were married $(76.7 \%), 52 \%$ had less than high school education, and $54.9 \%$ were retired. Hypertension was the most prevalent risk factor $(53.8 \%)$ followed by hypercholesterolemia $(50.6 \%)$ and physical inactivity $(47.1 \%)$ with differences in risk factors by diagnosis detailed in Table 1.
Patient-reported questionnaire score distributions (Table 2)

HeartQoL Mean HeartQoL HRQL scores for the total cohort were $2.0 \pm 0.7$ on the global scale, $1.9 \pm 0.8$ on the physical subscale and $2.2 \pm 0.8$ on the emotional subscale with ANCOVA results demonstrating significantly higher global scale and both physical and emotional score differences in patients with MI than patients with either AP or IHF.

MacNew The mean MacNew global HRQL score was $5.2 \pm 1.1$, the mean physical subscale score was $5.2 \pm 1.2$ and the mean emotional subscale score was $5.1 \pm 1.3$ in the total group. Using ANCOVA, there were significant score
Table 1 Patient characteristics: sociodemographic, risk factor, and intervention variables in patients with angina (AP), myocardial infarction (MI), or ischemic heart failure (IHF)

\begin{tabular}{|c|c|c|c|c|c|}
\hline & $\begin{array}{l}\text { Total cohort } \\
(N=472)\end{array}$ & $\begin{array}{l}\mathrm{AP} \\
(N=183 ; 38.8 \%)\end{array}$ & $\begin{array}{l}\text { MI } \\
(N=167 ; 35.4 \%)\end{array}$ & $\begin{array}{l}\mathrm{IHF} \\
(N=122 ; 25.8 \%)\end{array}$ & $P$ value \\
\hline \multicolumn{6}{|l|}{ Age } \\
\hline Years \pm SD & $65.4 \pm 12.5$ & $67.5 \pm 10.9$ & $63.1 \pm 11.4$ & $65.3 \pm 14.5$ & 0.004 \\
\hline \multicolumn{6}{|l|}{ Gender } \\
\hline Female & $120(25.4 \%)$ & $52(28.4 \%)$ & $36(21.5 \%)$ & $32(26.2 \%)$ & \multirow[t]{2}{*}{ ns } \\
\hline Male & $352(74.6 \%)$ & $131(72.6 \%)$ & $131(78.4 \%)$ & $90(73.8 \%)$ & \\
\hline \multicolumn{6}{|l|}{ Marital Status $(N=463)$} \\
\hline Single & $67(14.5 \%)$ & $26(14.6 \%)$ & $22(13.3 \%)$ & $19(15.8 \%)$ & \multirow[t]{3}{*}{ ns } \\
\hline Married/partnership & $355(76.7 \%)$ & $134(75.3 \%)$ & $129(78.2 \%)$ & $92(76.7 \%)$ & \\
\hline Other & $41(8.8 \%)$ & $18(10.1 \%)$ & $14(8.5 \%)$ & $9(7.5 \%)$ & \\
\hline \multicolumn{6}{|l|}{ Education $(N=460)$} \\
\hline$<$ High school & $239(51.9 \%)$ & $96(53.3 \%)$ & $82(50 \%)$ & $61(52.6 \%)$ & \multirow[t]{3}{*}{$\mathrm{ns}$} \\
\hline$=$ High school & $172(37.4 \%)$ & $68(37.8 \%)$ & $67(40.9 \%)$ & $37(31.9 \%)$ & \\
\hline$>$ High school & $49(10.7 \%)$ & $16(8.9 \%)$ & $15(9.2 \%)$ & $18(15.5 \%)$ & \\
\hline \multicolumn{6}{|l|}{ Employment $(N=461)$} \\
\hline Unemployed & $45(9.8 \%)$ & $14(7.82 \%)$ & $16(9.8 \%)$ & $15(12.6 \%)$ & ns \\
\hline Retired & $253(54.9 \%)$ & $113(63.1 \%)$ & $75(46.0 \%)$ & $65(54.6 \%)$ & ns \\
\hline Employed & $163(35.3 \%)$ & $52(29.1 \%)$ & $72(44.2 \%)$ & $39(32.8 \%)$ & 0.017 \\
\hline \multicolumn{6}{|l|}{ Risk factors } \\
\hline BMI & $27.0 \pm 4.7$ & $27.2 \pm 4.4$ & $26.9 \pm 4.4$ & $26.9 \pm 5.5$ & ns \\
\hline Diabetes $\S$ & $113(24.0 \%)$ & $49(26.9 \%)$ & $33(19.8 \%)$ & $31(25.6 \%)$ & ns \\
\hline Hypercholesterolemia ${ }^{\S}$ & $229(50.6 \%)$ & $88(50.6 \%)$ & $95(59.4 \%)$ & $46(38.7 \%)$ & 0.003 \\
\hline Hypertension ${ }^{\S}$ & $249(53.8 \%)$ & $108(60 \%)$ & $91(55.8 \%)$ & $50(41.7 \%)$ & 0.006 \\
\hline Physical inactivity \# & $213(47.1 \%)$ & $84(48.35)$ & $67(41.4 \%)$ & $62(53.4 \%)$ & ns \\
\hline Smoking & $79(17.2 \%)$ & $28(16 \%)$ & $30(18.1 \%)$ & $21(17.8 \%)$ & ns \\
\hline \multicolumn{6}{|l|}{ Intervention } \\
\hline PTCA & $166(35.5 \%)$ & $49(27.1 \%)$ & $101(60.5 \%)$ & $16(13.3 \%)$ & 0.001 \\
\hline CABG & $60(12.8 \%)$ & $32(17.6 \%)$ & $15(9 \%)$ & $13(10.7 \%)$ & 0.041 \\
\hline Valve surgery & $19(4.0 \%)$ & $4(2.2 \%)$ & $4(2.4 \%)$ & $11(9.1 \%)$ & 0.005 \\
\hline
\end{tabular}

$N$ number of patients (sub-group $N$ does not always $=472$ due to missing data)

$p$ value between diagnosis using Chi-square tests with categorical variables and ANCOVA with continuous variables (post hoc Bonferroni correction and scores adjusted for age, sex, and risk factors);

$B M I$ body mass index, ${ }^{\S}$ Physician reported, ${ }^{\#}$ Patient-reported active on $<3$ occasions per week, $P T C A$ percutaneous transluminal coronary angioplasty, $C A B G$ coronary artery bypass grafting 
Table 2 Scores (mean \pm standard deviation) on HeartQoL, Hospital Anxiety, and Depression Scale (HADS) and MacNew and percentage HADS anxious, depressed, and distressed in the total cohort and in patients with angina (AP), myocardial infarction (MI), or ischemic heart failure (IHF)

\begin{tabular}{|c|c|c|c|c|c|}
\hline & $\begin{array}{l}\text { Total cohort } \\
(N=472)\end{array}$ & $\begin{array}{l}\mathrm{AP} \\
(N=183 ; 38.8 \%)\end{array}$ & $\begin{array}{l}\text { MI } \\
(N=167 ; 35.4 \%)\end{array}$ & $\begin{array}{l}\mathrm{IHF} \\
(N=122 ; 25.8 \%)\end{array}$ & $P$-value \\
\hline \multicolumn{6}{|l|}{ HeartQoL } \\
\hline Global scale & $2.0 \pm 0.7$ & $1.9 \pm 0.7$ & $2.3 \pm 0.6$ & $1.7 \pm 0.8$ & $<0.001^{\mathrm{a}, \mathrm{b}}$ \\
\hline Physical subscale & $1.9 \pm 0.8$ & $1.9 \pm 0.8$ & $2.2 \pm 0.7$ & $1.6 \pm 0.9$ & $<0.001^{\mathrm{a}, \mathrm{b}}$ \\
\hline Emotional subscale & $2.2 \pm 0.8$ & $2.1 \pm 0.8$ & $2.3 \pm 0.7$ & $2.0 \pm 0.8$ & $<0.002^{\mathrm{a}, \mathrm{b}}$ \\
\hline \multicolumn{6}{|l|}{ MacNew } \\
\hline Global scale & $5.2 \pm 1.1$ & $5.1 \pm 1.0$ & $5.5 \pm 1.0$ & $4.9 \pm 1.1$ & $<0.001^{\mathrm{a}, \mathrm{b}}$ \\
\hline Physical subscale & $5.2 \pm 1.2$ & $5.1 \pm 1.2$ & $5.6 \pm 1.0$ & $4.9 \pm 1.2$ & $<0.001^{\mathrm{a}, \mathrm{b}}$ \\
\hline Emotional subscale & $5.1 \pm 1.3$ & $5.0 \pm 1.1$ & $5.3 \pm 1.1$ & $4.9 \pm 1.2$ & $<0.002^{\mathrm{a}, \mathrm{b}}$ \\
\hline \multicolumn{6}{|l|}{ HADS } \\
\hline Anxiety score & $5.2 \pm 3.9$ & $5.5 \pm 4.0$ & $5.0 \pm 4.1$ & $5.2 \pm 3.8$ & ns \\
\hline Anxious (score, $\geq 8$ ) & $130(27.1 \%)$ & $47(25.7 \%)$ & $46(27.5 \%)$ & $35(28.7 \%)$ & $\mathrm{ns}$ \\
\hline Depression score & $5.5 \pm 4.2$ & $5.7 \pm 4.0$ & $4.7 \pm 4.2$ & $6.3 \pm 4.4$ & $<0.001^{\mathrm{a}}$ \\
\hline Depressed (score, $\geq 8$ ) & $132(27.9 \%)$ & $57(30.4 \%)$ & $37(22.2 \%)$ & $39(32.2 \%)$ & ns \\
\hline General distress score & $10.7 \pm 7.4$ & $11.2 \pm 7.2$ & $9,7 \pm 7.6$ & $11.5 \pm 7.5$ & ns \\
\hline Distressed (score, $\geq 12$ ) & $194(41.1 \%)$ & $79(40.7 \%)$ & $58(29.9 \%)$ & $57(29.4 \%)$ & ns \\
\hline
\end{tabular}

$p$ value between diagnosis using ANCOVA (post hoc Bonferroni correction and scores adjusted for age, sex, and risk factors)

${ }^{a}$ MI vs. HF

${ }^{\mathrm{b}} \mathrm{MI}$ vs. AP

differences between patients with MI and those with either AP or IHF on the global scale and both physical and emotional subscales with patients with MI reporting higher HRQL than patients with either AP or IHF.

Hospital Anxiety and Depression Scale For the total cohort, the mean HADS anxiety score was $5.2 \pm 3.9$ with anxiety scores $\geq 8$ reported by $27.1 \%$ of the total cohort. The mean HADS depression score in the total cohort was $5.5 \pm 4.2$ with depression scores $\geq 8$ reported by $27.9 \%$ of the total cohort. The mean HADS general distress score in the total cohort was $10.7 \pm 7.4$ with general distress scores $\geq 12$ reported by $41.1 \%$ of the total cohort. Although patients with IHF reported significantly higher depression scores than patients with MI, the anxiety scores, the general distress scores and the proportions of patients with HADS anxiety or depression scores $\geq 8$ or general distress scores $\geq 12$ were not significantly different by diagnosis.

\section{Mokken scale factor structure (Table 3)}

With Mokken analysis, the HeartQoL H coefficients were rated as "strong" on the global scale (0.59) and on both the physical (0.67) and the emotional (0.68) subscales confirming the original HeartQoL two-factor structure. Of the HeartQoL Hi coefficients, $85.8 \%$ of the items on the global scale (12 of 14 items; Hi range, $0.47-0.66$ ) and $100 \%$ of the items on both the physical subscale (10 items; Hi range, 0.61 to 0.70 ) and the emotional subscale (4 items; Hi range, 0.63 to 0.72 ) were rated as "strong".

\section{HeartQoL floor and ceiling effects (Table 4)}

Floor effects on the HeartQoL global scale and both subscales were always $\leq 1.7 \%$ in the total group and in each diagnosis.

Ceiling effects on the HeartQoL global scale and the physical subscale were always $\leq 10.8 \%$ in the total group and in each diagnosis with moderate ceiling effects on the emotional subscale as high as $16.5 \%$ in the total group and $22.2 \%$ in patients with MI.

\section{Psychometric properties of the HeartQoL (Tables 2, $4,5, \& 6)$}

Reliability (Table 4) Internal consistency reliability was confirmed with Cronbach's alpha ranging from 0.87 to 0.94 in the total cohort, from 0.88 to 0.94 in patients with AP, from 0.86 to 0.93 in patients with MI and from 0.84 to 0.95 in patients with IHF. 
Table 3 Mokken scale analysis in in the total cohort for the HeartQoL items with Loevinger's $H i$ (item) and $H$ (scale) coefficients (strong, $\geq 0.50$, moderate, 0.49 to 0.40 )
Table 4 Italian HeartQoL floor and ceiling effects and internal consistency reliability (Cronbach's alpha) in the total cohort and in patients with angina (AP), myocardial infarction (MI), or ischemic heart failure (IHF)

\begin{tabular}{llll}
\hline Item & $\begin{array}{l}\text { Global Hi } \\
(N=433)\end{array}$ & $\begin{array}{l}\text { Physical Hi } \\
(N=460)\end{array}$ & $\begin{array}{l}\text { Emotional Hi } \\
(N=462)\end{array}$ \\
\hline 1. Walk indoors on level ground? & 0.57 & 0.64 & 0.70 \\
2. Garden. vacuum. or carry groceries? & 0.62 & 0.69 & \\
3. Climb a hill or a flight of stairs without stopping? & 0.62 & 0.70 & \\
4. Walk more than 100 yards at a brisk pace? & 0.62 & 0.68 & \\
5. Lift or move heavy objects? & 0.62 & 0.61 & 0.69 \\
6. Feeling short of breath? & 0.56 & 0.69 & 0.70 \\
7. Being physically restricted? & 0.66 & 0.67 & 0.63 \\
8. Feeling tired. fatigued. low on energy? & 0.65 & & 0.72 \\
9. Not feeling relaxed and free of tension? & 0.49 & & \\
10. Feeling depressed? & 0.47 & 0.63 & \\
11. Being frustrated? & 0.55 & 0.67 & \\
12. Being worried? & 0.53 & 0.67 & \\
13. Being limited in doing sports or exercise? & 0.60 & & \\
14. Working around the house or yard? & 0.61 & 0.59 & \\
HeartQoL H & & & \\
\hline
\end{tabular}

\begin{tabular}{lclll}
\hline HeartQoL & $\begin{array}{l}\text { Total cohort } \\
(N=472)\end{array}$ & $\begin{array}{l}\text { AP } \\
(N=183 ; 38.8 \%)\end{array}$ & $\begin{array}{l}\text { MI } \\
(N=167 ; 35.4 \%)\end{array}$ & $\begin{array}{l}\text { IHF } \\
(N=122 ; 25.8 \%)\end{array}$ \\
\hline Global scale & & & & \\
Floor effect & $0.4 \%$ & $1.0 \%$ & $0.6 \%$ & $1.0 \%$ \\
Ceiling effect & $4.7 \%$ & $3.8 \%$ & $7 \%$ & $2.50 \%$ \\
Cronbach's alpha & 0.94 & 0.94 & 0.93 & 0.94 \\
Physical subscale & & & & $1.0 \%$ \\
Floor effect & $0.6 \%$ & $1.0 \%$ & $1.2 \%$ & $4.90 \%$ \\
Ceiling effect & $7.4 \%$ & $6.0 \%$ & $10.8 \%$ & 0.95 \\
Cronbach's alpha & 0.94 & 0.93 & 0.92 & $1.6 \%$ \\
Emotional subscale & & & & $11.5 \%$ \\
Floor effect & $1.7 \%$ & $1.0 \%$ & $0.6 \%$ & 0.84 \\
Ceiling effect & $16.5 \%$ & $14.8 \%$ & $22.2 \%$ & 0.86 \\
Cronbach's alpha & 0.87 & 0.88 & & \\
\hline
\end{tabular}

$N$ number of patients;

Floor effect $>15 \%$ reporting poorest HRQL

Ceiling effect $>15 \%$ reporting highest HRQL
Convergent validity (Table 5) Convergent validity was confirmed in the total cohort and each diagnosis with correlations between the HeartQoL and MacNew physical subscales ranging from 0.71 to 0.75 and from 0.79 to 0.84 between the HeartQoL and MacNew emotional subscales. Correlations between dissimilar scales of both instruments were significantly lower according to Steiger's test for comparing Pearson correlations confirming divergent validity.

Discriminative validity (Tables 2, 6) Discriminative validity for the HeartQoL was fully confirmed for diagnosis, MacNew global HRQL scores, HADS anxiety, depression, and general distress, largely confirmed for sex, and essentially not confirmed for age.
Diagnosis (Table 2): Patients with MI reported significantly higher HeartQoL global scale and both physical and emotional subscale scores than patients with either AP or IHF.

MacNew (Table 6): Patients reporting higher MacNew global HRQL scores (top 33\% of actual scores reported significantly higher HeartQoL global and both physical and emotional subscale scores than patients reporting lower MacNew global HRQL scores (bottom 33\% of actual scores).

HADS anxiety (Table 6): Significantly higher HeartQoL global scale and both physical and emotional subscale scores 
Table 5 Convergent validity of the Italian HeartQoL subscales with the MacNew subscales in the total cohort and in patients with angina pectoris (AP), myocardial infarction (MI), or ischemic heart failure (IHF)

\begin{tabular}{|c|c|c|c|}
\hline & \multicolumn{3}{|l|}{ HeartQoL } \\
\hline & Physical subscale & $\begin{array}{l}\text { Emotional sub- } \\
\text { scale }\end{array}$ & $p$-value\# \\
\hline \multicolumn{4}{|c|}{ Total cohort $(N=472)$} \\
\hline $\begin{array}{l}\text { MacNew Physi- } \\
\text { cal }\end{array}$ & 0.75 & 0.70 & 0.05 \\
\hline $\begin{array}{l}\text { MacNew Emo- } \\
\text { tional }\end{array}$ & 0.57 & 0.81 & $<0.001$ \\
\hline$p$ value\# & $<0.001$ & $<0.001$ & \\
\hline \multicolumn{4}{|l|}{$\operatorname{AP}(N=183)$} \\
\hline $\begin{array}{l}\text { MacNew Physi- } \\
\text { cal }\end{array}$ & 0.74 & 0.71 & 0.427 \\
\hline $\begin{array}{l}\text { MacNew Emo- } \\
\text { tional }\end{array}$ & 0.59 & 0.81 & $<0.001$ \\
\hline$p$ value\# & $<0.01$ & $<0.05$ & \\
\hline \multicolumn{4}{|l|}{$\mathrm{MI}(N=167)$} \\
\hline $\begin{array}{l}\text { MacNew Physi- } \\
\text { cal }\end{array}$ & 0.71 & 0.72 & 0.094 \\
\hline $\begin{array}{l}\text { MacNew Emo- } \\
\text { tional }\end{array}$ & 0.57 & 0.84 & $<0.001$ \\
\hline$p$ value\# & $<0.05$ & $<0.01$ & \\
\hline \multicolumn{4}{|l|}{$\operatorname{IHF}(N=122)$} \\
\hline $\begin{array}{l}\text { MacNew Physi- } \\
\text { cal }\end{array}$ & 0.73 & 0.64 & 0.274 \\
\hline $\begin{array}{l}\text { MacNew Emo- } \\
\text { tional }\end{array}$ & 0.51 & 0.79 & $<0.001$ \\
\hline$p$ value\# & $<0.01$ & $<0.01$ & \\
\hline
\end{tabular}

$N$ number of patients;

Strong Pearson's correlation coefficients between similar HeartQoL and MacNew subscales are bolded; all correlation coefficients, $p<0.01$

${ }^{\text {\#}}$ Steiger's test for comparing Pearson's correlations

were observed in patients who were not anxious than in patients who were anxious;

HADS depression (Table 6): Patients who were not depressed reported significantly higher HeartQoL global scale and both physical and emotional subscale scores than reported by patients who were depressed $(p<0.001)$;

HADS distress (Table 6): Significantly higher HeartQoL global scale, physical, and emotional subscale scores were observed in patients who were not distressed than in patients who were distressed;

Sex (Table 6): In the total group, female patients reported significantly higher HeartQoL global scale and both physical and emotional subscale scores than male patients; HeartQoL global scale and emotional subscale scores were significantly higher in females than males in patients with AP and in patients with IHF; in patients with MI, HeartQoL global scale and physical subscale scores were significantly higher in females than males.

Age (Table 6): The only significant HeartQoL score difference by age was a higher physical HeartQoL subscale score in middle-aged patients compared to elderly patients in the total group.

\section{Discussion}

The Italian-language version of the 14-item HeartQoL questionnaire demonstrated adequate internal consistency, convergent, divergent and discriminative validity and therefore may be recommended for the use in clinical practice and research to assess and compare HRQL in Italian-speaking IHD patients with AP, MI or IHF. The psychometric properties of the Italian version of the HeartQoL were evaluated on a sample of 472 patients with either AP, MI or IHF from five Italian centres in North-East, North-West, Central, and Southern Italy and therefore largely representative of the demographic, social, cultural, and economic characteristics of the Italian population. Further, these psychometric properties are consistent with the original validation study in patients with AP, MI or IHF, [13] the English HeartQoL version based on patients with AP or MI in the USA, [30] the German HeartQoL version in patients with AP, MI or IHF, [14] The Iranian HeartQoL version in patients with MI, [31] the EuroAspire IV study in chronic coronary syndrome patients [32] and also with validation studies in patients with atrial fibrillation, [16] implantable cardioverter defibrillator recipients [17] or following valve surgery [18]. In addition, the original two-factor structure [12], determined with Mokken scale analysis [27], was confirmed with strong physical (Hi 0.67) and emotional (Hi 0.68) domains being comparable with the original [13] and more recent validation studies. [14, 16, 17, 30, 32].

With higher HRQL scores (range 0-3) indicating better HRQL, the mean HRQL scores in the Italian HeartQoL total group were $2.0 \pm 0.07$ on the global scale, $1.9 \pm 0.08$ on the physical subscale and $2.1 \pm 0.08$ on the emotional subscale and all scores reported by patients with $\mathrm{MI}$ indicated significantly better HRQL than reported by patients with either AP or IHF. With moderate floor and ceiling effects present when $>15 \%$ patients report the lowest score $(=0$; floor $)$ or the highest score (=3; ceiling), [26] floor and ceiling effects on the global scale and physical subscale in the total group and each diagnosis were minimal indicating detection of both deterioration and improvement. However, with the emotional subscale, although all floor effects and ceiling effects in patients with AP or IHF were minimal, the ceiling effects were moderate in the total group and in patients with MI indicating limited detection of improvement. As this outcome is consistent with the original HeartQoL study [13] 
Table 6 Discriminative validity of the Italian HeartQoL in the total cohort and in patients with angina pectoris (AP), myocardial infarction (MI), or ischemic heart failure (IHF)

\begin{tabular}{|c|c|c|c|}
\hline HeartQoL & Global scale & Physical subscale & Emotional subscale \\
\hline \multicolumn{4}{|l|}{ Total cohort $(\mathrm{N}=472)$} \\
\hline \multicolumn{4}{|l|}{ Age } \\
\hline Young $(N=148)$ & $2.08[1.96-2.20]$ & $2.1[1.92-2.18]$ & $2.17[2.04-2.30]$ \\
\hline Middle-age $(N=162)$ & $2.01[1.90-2.13]$ & $1.95[1.83-2.08]$ & $2.16[2.04-2.28]$ \\
\hline Elderly $(N=151)$ & $1.89[1.78-2.01]$ & $1.78[1.65-1.91]$ & $2.18[2.06-2.30]$ \\
\hline$p$ value & ns & $<.05$ & $\mathrm{~ns}$ \\
\hline \multicolumn{4}{|l|}{ Sex } \\
\hline Female $(N=120)$ & $2.09[2.01-2.17]$ & $2.02[1.94-2.11]$ & $2.25[2.17-2.32]$ \\
\hline Male $(N=351)$ & $1.71[1.58-1.85]$ & 1.63 [1.49-1.77] & $1.92[1.78-2.09]$ \\
\hline$p$ value & $<.001$ & $<.001$ & $<.001$ \\
\hline \multicolumn{4}{|l|}{ MacNew_global score } \\
\hline Top tertile $(N=154)$ & $2.60[2.54-2.63]$ & $2.52[2.45-2.60]$ & $2.77[2.73-2.81]$ \\
\hline Bottom tertile $(N=157)$ & $1.29[1.20-1.39]$ & $1.25[1.14-1.36]$ & $1.40[1.29-1.52]$ \\
\hline$p$ value & $<.001$ & $<.001$ & $<.001$ \\
\hline \multicolumn{4}{|l|}{$H A D S^{*}$} \\
\hline Anxious $(N=128)$ & $1.40[1.28-1.53]$ & $1.43[1.30-1.57]$ & $1.33[1.20-1.46]$ \\
\hline Not anxious $(N=343)$ & $2.21[2.15-2.28]$ & $2.11[2.03-2.19]$ & $2.47[2.41-2.53]$ \\
\hline$p$ value & $<.001$ & $<.001$ & $<.001$ \\
\hline Depressed $(N=131)$ & 1.37 [1.25-1.49] & $1.36[1.22-1.49]$ & $1.41[1.27-1.54]$ \\
\hline Not depressed $(N=337)$ & $2.24[2.18-2.31]$ & $2.15[2.07-2.23]$ & $2.46[2.41-2.52]$ \\
\hline$p$ value & $<.001$ & $<.001$ & $<.001$ \\
\hline Stressed $(N=194)$ & 1.48 [1.39-1.58] & $1.46[1.35-2.58]$ & $1.53[1.43-1.64]$ \\
\hline Not stressed $(N=227)$ & $2.35[2.29-2.41]$ & $2.25[2.17-2.34]$ & $2.60[2.56-2.65]$ \\
\hline$p$ value & $<.001$ & $<.001$ & $<.001$ \\
\hline \multicolumn{4}{|l|}{$\operatorname{AP}(N=183)$} \\
\hline \multicolumn{4}{|l|}{ Age } \\
\hline Young $(N=41)$ & $1.95[1.71-2.20]$ & $1.93[1.67-2.20]$ & $2.02[1.73-2.30]$ \\
\hline Middle age $(N=64)$ & $1.97[1.79-2.15]$ & $1.92[1.72-2.12]$ & 2.10 [1.92-2.29] \\
\hline Elderly $(N=74)$ & $1.90[1.73-2.07]$ & $1.79[1.60-1.97]$ & 2.17 [1.99-2.35] \\
\hline$p$ value & ns & ns & ns \\
\hline \multicolumn{4}{|l|}{$\operatorname{Sex}$} \\
\hline Female $(N=52)$ & $2.00[1.88-2.13]$ & 1.93 [1.79-2.07] & $2.17[2.04-2.31]$ \\
\hline Male $(N=130)$ & 1.74 [1.53-1.95] & 1.68 [1.46-1.90] & $1.90[1.67-2.12]$ \\
\hline$p$ value & $<.05$ & ns & $<.05$ \\
\hline \multicolumn{4}{|l|}{ MacNew_global } \\
\hline Top tertile $(N=70)$ & $2.60[2.50-2.69]$ & $2.52[2.39-2.65]$ & $2.78[2.70-2.85]$ \\
\hline Bottom tertile $(N=51)$ & 1.33 [1.17-1.49] & $1.30[1.12-1.48]$ & $1.42[1.23-1.61]$ \\
\hline$p$ value & $<.001$ & $<.001$ & $<.001$ \\
\hline \multicolumn{4}{|l|}{$H A D S^{*}$} \\
\hline Anxious $(N=47)$ & $1.32[1.10-1.55]$ & 1.38 [1.13-1.62] & $1.20[0.96-1.43]$ \\
\hline Not anxious $(N=135)$ & $2.14[2.03-2.24]$ & $2.03[1.91-2.15]$ & $2.41[2.32-2.49]$ \\
\hline$p$ value & $<.001$ & $<.001$ & $<.001$ \\
\hline Depressed $(N=55)$ & 1.35 [1.16-1.53] & 1.33 [1.13-1.53] & $1.40[1.18-1.61]$ \\
\hline Not depressed $(N=125)$ & $2.19[2.08-2.30]$ & $2.10[1.98-2.23]$ & $2.41[2.31-2.51]$ \\
\hline$p$ value & $<.001$ & $<.001$ & $<.001$ \\
\hline Stressed $(N=79)$ & $1.45[1.30-1.61]$ & $1.44[1.27-1.62]$ & $1.48[1.31-1.65]$ \\
\hline Not stressed $(N=103)$ & $2.29[2.19-2.40]$ & $2.18[2.05-2.31]$ & 2.57 [2.48-2.65] \\
\hline$p$ value & $<.001$ & $<.001$ & $<.001$ \\
\hline \multicolumn{4}{|l|}{ MI $(N=167)$} \\
\hline \multicolumn{4}{|l|}{ Age } \\
\hline Young $(N=66)$ & $2.31[2.14-2.47]$ & $2.29[2.12-2.47]$ & $2.34[2.16-2.51]$ \\
\hline Middle age $(N=59)$ & $2.29[2.14-2.44]$ & $2.26[2.10-2.42]$ & $2.36[2.18-2.53]$ \\
\hline Elderly $(N=38)$ & $2.13[1.92-2.34]$ & 2.06 [1.82-2.29] & $2.31[2.08-2.54]$ \\
\hline$p$ value & ns & ns & ns \\
\hline
\end{tabular}


Table 6 (continued)

\begin{tabular}{|c|c|c|c|}
\hline HeartQoL & Global scale & Physical subscale & Emotional subscale \\
\hline \multicolumn{4}{|l|}{ Sex } \\
\hline Female $(N=36)$ & $2.33[2.23-2.43]$ & $2.31[2.21-2.42]$ & $2.36[2.24-2.48]$ \\
\hline Male $(N=131)$ & $2.00[1.77-2.22]$ & $1.91[1.66-2.16]$ & $2.22[1.98-2.45]$ \\
\hline$p$ value & $<.005$ & $<.001$ & ns \\
\hline \multicolumn{4}{|l|}{ MacNew-global } \\
\hline Top tertile $(N=77)$ & $2.63[2.56-2.70]$ & 2.57 [2.47-2.67] & $2.77[2.71-2.84]$ \\
\hline Bottom tertile $(N=34)$ & $1.40[1.22-1.58]$ & 1.44 [1.23-1.64] & $1.32[1.08-1.55]$ \\
\hline$p$ value & $<.001$ & $<.001$ & $<.001$ \\
\hline \multicolumn{4}{|l|}{ HADS* } \\
\hline Anxious $(N=46)$ & 1.71 [1.52-1.89] & 1.76 [1.56-1.96] & $1.57[1.36-1.78]$ \\
\hline Not anxious $(N=121)$ & $2.47[2.38-2.55]$ & $2.40[2.30-2.51]$ & $2.62[2.54-2.70]$ \\
\hline$p$ value & $<.001$ & $<.001$ & $<.001$ \\
\hline Depressed $(N=37)$ & $1.67[1.44-1.90]$ & $1.72[1.47-1.96]$ & $1.53[1.25-1.81]$ \\
\hline Not depressed $(N=130)$ & $2.43[2.34-2.51]$ & $2.37[2.27-2.47]$ & $2.56[2.48-2.64]$ \\
\hline$p$ value & $<.001$ & $<.05$ & $<.001$ \\
\hline Stressed $(N=58)$ & $1.77[1.60-1.93]$ & $1.79[1.61-1.98]$ & $1.70[1.50-1.90]$ \\
\hline Not stressed $(\mathrm{N}=109)$ & $2.52[2.44-2.60]$ & $2.46[2.36-2.56]$ & $2.67[2.60-2.73]$ \\
\hline$p$ value & $<.001$ & $<.001$ & $<.001$ \\
\hline \multicolumn{4}{|l|}{$\operatorname{IHF}(N=122)$} \\
\hline \multicolumn{4}{|l|}{ Age } \\
\hline Young $(N=41)$ & 1.85 [1.62-2.09] & $1.77[1.50-2.05]$ & 2.04 [1.79-2.29] \\
\hline Middle age $(N=39)$ & $1.66[1.40-1.92]$ & $1.54[1.25-1.82]$ & $1.96[1.68-2.25]$ \\
\hline Elderly $(N=39)$ & $1.66[1.40-1.91]$ & 1.49 [1.19-1.79] & $2.08[1.84-2.31]$ \\
\hline$p$ value & ns & ns & ns \\
\hline \multicolumn{4}{|l|}{ Sex } \\
\hline Female $(N=32)$ & $1.87[1.71-2.03]$ & 1.93 [1.79-2.07] & $2.17[2.04-2.31]$ \\
\hline Male $(N=90)$ & 1.35 [1.11-1.59] & $1.68[1.46-1.90]$ & $1.90[1.67-2.12]$ \\
\hline$p$ value & $<.001$ & ns & $<.05$ \\
\hline \multicolumn{4}{|l|}{ MacNew_global } \\
\hline Top tertile $(N=43)$ & $2.50[2.32-2.69]$ & $2.40[2.13-2.66]$ & $2.77[2.68-2.86]$ \\
\hline Bottom tertile $(N=26)$ & $1.17[1.01-1.33]$ & $1.06[0.87-1.26]$ & $1.44[1.24-1.63]$ \\
\hline$p$ value & $<.001$ & $<.001$ & $<.001$ \\
\hline \multicolumn{4}{|l|}{ HADS* } \\
\hline Anxious $(N=35)$ & $1.12[0.93-1.31]$ & $1.38[1.13-1.62]$ & $1.20[0.96-1.43]$ \\
\hline Not anxious $(N=87)$ & $1.98[1.83-2.14]$ & $2.03[1.91-2.15]$ & $2.41[2.32-2.49]$ \\
\hline$p$ value & $<.001$ & $<.001$ & $<.001$ \\
\hline Depressed $(N=39)$ & $1.13[0.93-1.33]$ & $1.33[1.13-1.53]$ & $1.40[1.18-1.61]$ \\
\hline Not depressed $(N=81)$ & $2.03[1.88-2.18]$ & $2.10[1.98-2.23]$ & $2.41[2.31-2.51]$ \\
\hline$p$ value & $<.001$ & $<.001$ & $<.001$ \\
\hline Stressed $(N=57)$ & $1.24[1.07-1.41]$ & $1.44[1.27-1.62]$ & $1.48[1.31-1.65]$ \\
\hline Not stressed $(N=65)$ & $2.17[2.02-2.32]$ & $2.18[2.05-2.31]$ & $2.57[2.48-2.65]$ \\
\hline$p$ value & $<.001$ & $<.001$ & $<.001$ \\
\hline
\end{tabular}

$\mathrm{N}$ Number of patients

Young, $<60$ years; Middle-age, $60-70$ years; Elderly, $>70$ years

\#Middle-age versus elderly

Mean (95\% confidence interval) comparisons with ANCOVAs (scores adjusted for age, sex, risk factors, and disease severity within diagnosis) and post hoc Bonferroni correction;

*HADS Hospital Anxiety and Depression Scale with cut-off score $\geq 8$ for the anxiety/depression subscales and $\geq 12$ for the general distress factor 
and other validation studies [14, 16-18, 30, 32] assessing improvement in HeartQoL emotional HRQL may be more challenging than either global or physical HRQL.

The Italian HeartQoL demonstrated high internal consistency reliability for each subscale, exceeding the recommended criterion of 0.70 for group HRQL comparisons with Cronbach's $\alpha \geq 0.92$ on both the global scale and physical subscale and $\geq 0.84$ on the emotional subscale in the total group and each of the three diagnoses. This is consistent with the previous validation studies [14, 16, 17, 30, 32] indicating that the items captured in the HeartQoL reflect the same constructs. Convergent validity refers to how closely scales measuring similar constructs are correlated, and was demonstrated across diagnostic groups with strong correlations $(r>0.70)$ between the physical and emotional subscales of HeartQoL and corresponding subscales of MacNew; with significantly lower correlations between dissimilar constructs, divergent validity was also confirmed.

Discriminative validity was determined using the 'known groups' approach [26] with the expectation that HRQL scores would distinguish between pre-identified groups. Of the total of 84 discriminative validity calculations in the total cohort and each diagnosis, 70 (83\%) were fully confirmed; of the 14 calculations that were not significant, 11 (79\%) were on the age and $3(21 \%)$ on the sex variables. The discriminative validity of the Italian HeartQoL was fully confirmed for diagnosis as patients with MI reported significantly higher HeartQoL scores than patients with either AP or IHF which is largely consistent with both the original validation study [13] and the German validation study [14] as well as in the English HeartQoL where patients with MI reported higher HRQL scores than did patients with AP. [30] Discriminative validity was also fully confirmed with HADS anxiety/depression scales in the total group and in each diagnosis which is consistent for HADS anxiety and depression in the original study [13] and previously published HeartQoL studies. [14, 16-18, 30, 32] As reported in the German HeartQoL validation publication [14] the Italian HeartQoL HRQL scores were significantly higher in patients not reporting HADS distress compared to those reporting distress. Discriminative validity was largely confirmed for sex in this study with females reporting significantly better HRQL than males but this is not consistent with the EuroAspire IV study in chronic coronary syndrome patients [32], the German HeartQoL observations in patients with AP, MI or IHF [14] or the studies in Danish patients with atrial fibrillation [16] or following valve surgery [18] where males reported higher HRQL, although not always significant, than females. Finally, except for significantly higher physical HeartQoL scores in middle-aged patients than in elderly patients, discriminative validity was not confirmed for age in the present study. There was a trend for lower HRQL to be reported by elderly Italian patients which is largely consistent with the EuroAspire IV study [32] but not with the German HeartQoL observations [14] where the hypothesized lower HRQL scores in older patients was not consistently met.

\section{Limitations and strengths of the study}

In every questionnaire with a relatively small number of items per scale, the amplitude of assessment of differences or changes in HRQL may be limited. Furthermore, examination of test-retest reproducibility was not possible with the cross-sectional design of the study which is also the major limitation of the present validation study not allowing for the determination of responsiveness. Future studies will be needed to determine the evaluative validity of the Italian HeartQoL questionnaire. The strength of the study lies in the demonstration of adequate key psychometric attributes of internal consistency reliability and convergent, divergent, and discriminative validity in Italian-speaking patients with ischemic heart disease.

\section{Conclusion}

The Italian version of the HeartQoL questionnaire demonstrated satisfactory psychometric characteristics showing excellent internal consistency reliability and adequate convergent, divergent, and discriminative validity in Italian speaking patients with IHD and its three major diagnoses (AP, MI, and IHF). The Italian HeartQoL can be recommended to clinicians and researchers to estimate and compare the impact of IHD on patients' HRQL.

Acknowledgements Link to access the Italian HeartQoL: https://www. escardio.org/Education/Practice-Tools/CVD-prevention-toolbox/Heart QoL.

Author contributions N.O. and F.F. designed the study. S.H. performed the data analysis. M.E.A., G.B., F.G., D.M., C.V., L.P., F.T collected the data. A.A wrote the manuscript with the support of F.F. and N.O. N.M supervised the project and revised the manuscript. All authors provided critical feedback and approved the manuscript for publication.

Funding Open access funding provided by Università degli Studi di Firenze within the CRUI-CARE Agreement.

\section{Declarations}

Conflict of interest The authors declare that they have no conflict of interest or any competing interests.

Ethics approval This study was approved by either the respective ethics committees or Institutional Review Boards. 
Informed consent Written informed consent was obtained from all individual participants included in the study.

Open Access This article is licensed under a Creative Commons Attribution 4.0 International License, which permits use, sharing, adaptation, distribution and reproduction in any medium or format, as long as you give appropriate credit to the original author(s) and the source, provide a link to the Creative Commons licence, and indicate if changes were made. The images or other third party material in this article are included in the article's Creative Commons licence, unless indicated otherwise in a credit line to the material. If material is not included in the article's Creative Commons licence and your intended use is not permitted by statutory regulation or exceeds the permitted use, you will need to obtain permission directly from the copyright holder. To view a copy of this licence, visit http://creativecommons.org/licenses/by/4.0/.

\section{References}

1. Crossing the Quality Chasm: A New Health System for the 21st Century. National Academies Press; 2001:10027. doi:https://doi. org/10.17226/10027

2. Knuuti J, Wijns W, Saraste A et al (2020) 2019 ESC Guidelines for the diagnosis and management of chronic coronary syndromes. Eur Heart J 41(3):407-477. https://doi.org/10.1093/eurheartj/ ehz425

3. CDER Patient-Focused Drug Development I FDA. Accessed February 4, 2021. https://www.fda.gov/drugs/development-approvalprocess-drugs/cder-patient-focused-drug-development

4. Anker SD, Agewall S, Borggrefe M et al (2014) The importance of patient-reported outcomes: a call for their comprehensive integration in cardiovascular clinical trials. Eur Heart J 35(30):20012009. https://doi.org/10.1093/eurheartj/ehu205

5. Rumsfeld JS, Alexander KP, Goff DC et al (2013) Cardiovascular health: the importance of measuring patient-reported health status: a scientific statement from the american heart association. Circulation 127(22):2233-2249. https://doi.org/10.1161/CIR. 0b013e3182949a2e

6. Deshpande P, Sudeepthi Bl, Rajan S, Abdul Nazir C. Patientreported outcomes: A new era in clinical research. Perspect Clin Res. 2011;2(4):137. doi:https://doi.org/10.4103/2229-3485.86879

7. Ware JE, Gandek B (1998) Overview of the SF-36 Health Survey and the International Quality of Life Assessment (IQOLA) Project. J Clin Epidemiol 51(11):903-912. https://doi.org/10.1016/ S0895-4356(98)00081-X

8. Ware JE, Kosinski M. SF-36 Physical \& Mental Health Summary Scales: A Manual for Users of Version 1. QualityMetric; 2005.

9. Spertus JA, Winder JA, Dewhurst TA et al (1995) Development and evaluation of the Seattle Angina questionnaire: a new functional status measure for coronary artery disease. J Am Coll Cardiol 25(2):333-341. https://doi.org/10.1016/0735-1097(94) 00397-9

10. Rector TS, Kubo SH, Cohn JN (1993) Validity of the minnesota living with heart failure questionnaire as a measure of therapeutic response to enalapril or placebo. Am J Cardiol 71(12):1106-1107. https://doi.org/10.1016/0002-9149(93)90582-W

11. Höfer S, Lim L, Guyatt G, Oldridge N (2004) The MacNew heart disease health-related quality of life instrument: a summary. Health Qual Life Outcomes 2(1):3. https://doi.org/10.1186/ 1477-7525-2-3

12. Oldridge N, Höfer S, McGee H et al (2014) The HeartQoL: Part I. Development of a new core health-related quality of life questionnaire for patients with ischemic heart disease. Eur J Prev Cardiolog. 21(1):90-97. https://doi.org/10.1177/2047487312450544
13. Oldridge N, Höfer S, McGee H et al (2014) The HeartQoL: Part II Validation of a new core health-related quality of life questionnaire for patients with ischemic heart disease. Eur J Prev Cardiolog. 21(1):98-106. https://doi.org/10.1177/2047487312450545

14. Huber A, Oldridge N, Benzer W, Saner H, Höfer S (2020) Validation of the German HeartQoL: a short health-related quality of life questionnaire for cardiac patients. Qual Life Res 29(4):10931105. https://doi.org/10.1007/s11136-019-02384-6

15. Luan $\mathrm{L}, \mathrm{Hu} \mathrm{H}$, Oldridge $\mathrm{N}$, et al. The psychometric evaluation of the Chinese version HeartQoL Questionnaire among patients with ischemic Heart disease in China. Submitted to Value in HealthAsian Region.

16. Kristensen MS, Zwisler A-D, Berg SK et al (2016) Validating the HeartQoL questionnaire in patients with atrial fibrillation. Eur $\mathbf{J}$ Prev Cardiolog 23(14):1496-1503. https://doi.org/10.1177/20474 87316638485

17. Zangger G, Zwisler A-D, Kikkenborg Berg S et al (2018) Psychometric properties of HeartQoL, a core heart disease-specific health-related quality of life questionnaire, in Danish implantable cardioverter defibrillator recipients. Eur J Prev Cardiolog 25(2):142-149. https://doi.org/10.1177/2047487317733074

18. Grønset CN, Thygesen LC, Berg SK et al (2019) Measuring HRQoL following heart valve surgery: the HeartQoL questionnaire is a valid and reliable core heart disease instrument. Qual Life Res 28(5):1245-1253. https://doi.org/10.1007/ s11136-018-02098-1

19. Lohr KN (2002) Assessing health status and quality-of-life instruments: attributes and review criteria. Qual Life Res 11(3):193205. https://doi.org/10.1023/A:1015291021312

20. Campeau L (1976) Letter: Grading of angina pectoris. Circulation 54(3):522-523. https://doi.org/10.1161/circ.54.3.947585

21. Costantini M, Musso M, Viterbori P et al (1999) Detecting psychological distress in cancer patients: validity of the Italian version of the Hospital Anxiety and Depression Scale. Support Care Cancer 7(3):121-127. https://doi.org/10.1007/s005200050241

22. Palacios JE, Khondoker M, Achilla E, Tylee A, Hotopf M (2016) A single, one-off measure of depression and anxiety predicts future symptoms, higher healthcare costs, and lower quality of life in coronary heart disease patients: analysis from a multi-wave, primary care cohort study. Hashimoto K, ed. PLoS ONE.;11(7):e0158163. Doi:https://doi.org/10.1371/journal.pone. 0158163

23. Oldridge N, Guyatt G, Jones N et al (1991) Effects on quality of life with comprehensive rehabilitation after acute myocardial infarction. Am J Cardiol 67(13):1084-1089. https://doi.org/10. 1016/0002-9149(91)90870-Q

24. Valenti L, Lim L, Heller RF, Knapp J (1996) An improved questionnaire for assessing quality of life after acute myocardial infarction. Qual Life Res 5(1):151-161. https://doi.org/10.1007/BF004 35980

25. Fattirolli F, Marchionni N, Höfer S et al (2015) The Italian MacNew heart disease health-related quality of life questionnaire: a validation study. Intern Emerg Med 10(3):359-368. https://doi. org/10.1007/s11739-015-1203-y

26. Terwee CB, Bot SDM, de Boer MR et al (2007) Quality criteria were proposed for measurement properties of health status questionnaires. J Clin Epidemiol 60(1):34-42. https://doi.org/10. 1016/j.jclinepi.2006.03.012

27. Meijer RR, Baneke JJ (2004) Analyzing psychopathology items: a case for nonparametric item response theory nglishg. Psychol Methods 9(3):354-368. https://doi.org/10.1037/1082-989X.9.3. 354

28. Taber KS (2018) The use of cronbach's alpha when developing and reporting research instruments in science education. Res Sci Educ 48(6):1273-1296. https://doi.org/10.1007/s11165-016-9602-2 
29. Steiger JH (1980) Testing pattern hypotheses on correlation matrices: alternative statistics and some empirical results. Multivar Behav Res 15(3):335-352. https://doi.org/10.1207/s15327906m br1503_7

30. Oldridge N, Cho C, Thomas R, Low M, Höfer S (2018) Validation of the nglish version of the heartqol health-related quality of life questionnaire in patients with coronary heart disease. J Cardiopulm Rehabil Prev 38(2):92-99. https://doi.org/10.1097/ HCR.0000000000000248

31. Ranjandish F, Mahmoodi H, Shaghaghi A (2019) Psychometric responsiveness of the health-related quality of life questionnaire (HeartQoL-P) in the Iranian post-myocardial infarction patients.
Health Qual Life Outcomes 17(1):10. https://doi.org/10.1186/ s12955-018-1075-8

32. De Smedt D, Clays E, Höfer S et al (2016) Validity and reliability of the HeartQoL questionnaire in a large sample of stable coronary patients: the EUROASPIRE IV study of the European society of cardiology. Eur J Prev Cardiolog 23(7):714-721. https://doi. org/10.1177/2047487315604837

Publisher's Note Springer Nature remains neutral with regard to jurisdictional claims in published maps and institutional affiliations. 